\title{
Stratégie scripturale et activité conceptuelle : analyse de quelques indicateurs langagiers dans des écrits scientifiques de collégiens à visée comparative
}

\section{Soledad Valera-Kummer et Caroline Masseron}

\section{(2) OpenEdition}

Journals

Édition électronique

URL : http://journals.openedition.org/pratiques/1401

DOI : $10.4000 /$ pratiques. 1401

ISSN : 2425-2042

Éditeur

Centre de recherche sur les médiations (CREM)

Édition imprimée

Date de publication : 15 décembre 2009

Pagination : 83-110

Référence électronique

Soledad Valera-Kummer et Caroline Masseron, « Stratégie scripturale et activité conceptuelle : analyse de quelques indicateurs langagiers dans des écrits scientifiques de collégiens à visée comparative », Pratiques [En ligne], 143-144 | 2009, mis en ligne le 19 juin 2014, consulté le 01 mai 2019. URL : http:// journals.openedition.org/pratiques/1401; DOI : 10.4000/pratiques.1401 


\section{Stratégie scripturale et activité conceptuelle : analyse de quelques indicateurs langagiers dans des écrits scientifiques de collégiens à visée comparative}

\section{Soledad Valera-Kummer}

Collège des Colombières, Genève

Caroline Masseron

Université Paul Verlaine, Metz, CELTED, EA 3474

Cet article s'inscrit dans une tradition déjà bien établie de collaboration pluridisciplinaire entre les didacticiens des sciences (Astolfi et Develay 1989, Jacobi 2005) et les didacticiens du français (Laparra 1986, Halté 1988, Garcia-Debanc 1990). Les uns et les autres se sont facilement convaincus de l'apport réciproque entre conduite verbale et formation de concept, au cours d'une démarche expérimentale ayant valeur de situation d'apprentissage. Et c'est ainsi que de nombreux travaux ont déjà témoigné de la nécessité de relayer les étapes de la conceptualisation scientifique des apprenants par une réflexion didactique sur les compétences langagières et discursives prises au sens large, par exemple plusieurs livraisons d'Aster parmi lesquelles nous citerons le $\mathrm{n}^{\circ} 6$, "Les élèves et l'écriture en sciences »(1988), le $n^{\circ} 33$, «Écrire pour comprendre les sciences » (2001) et le $n^{\circ} 37$ « Interactions langagières » (2003).

Notre étude restreint ses investigations à la description et à la comparaison. La comparaison est une «procédure » avérée dans les deux domaines disciplinaires convoqués, la biologie et l'analyse linguistique de l'écrit produit. Dans le premier cas, la comparaison a plutôt statut méthodologique et épistémologique (voir, comprendre, interpréter les données par différence), dans le second, elle tient de la figure de pensée (l'analogie et la ressemblance). Dans les deux cas, la comparaison offre l'intérêt de relever à la fois du raisonnement et de l'écriture. Dans cette mesure, on avance l'hypothèse que les formes d'énoncés et les unités lexicales qui seront prises dans le foyer de la visée comparative du discours constitueront des éléments précieux pour dresser un premier état des corrélations entre maîtrise conceptuelle et gestion discursive et pour envisager les solutions auxquelles recourent les collégiens comme des indicateurs de stratégie scripturale (Masseron 2005). Quant à la description, dans ses liens avec l'observation, elle constitue un préalable dans l'ordre de la complexité (l'objet et le raisonnement). L'ordonnancement des unités de la série (les thèmes), le contenu et la structure des prédicats 
de qualité, qui composent une séquence descriptive, nous ont paru préfigurer les données qui sont à l'œuvre, mais plus implicitement, dans une comparaison.

L'article s'appuie sur une sélection de productions écrites de collégiens (11-14 ans) qui ont porté sur le laurel ou le houx ${ }^{(1)}$ (un rameau présent lors de l'activité), la bactérie et le virus (comparaison par le biais de définitions); puis, au sujet de la seule bactérie, restitution d'une expérience et comparaison de variables introduites dans les conditions d'une expérimentation. On espère de ces différents paramètres (concret / abstrait ; description / raisonnement ; tâche simple / tâche complexe) qu'ils permettront d'établir un bilan didactique au sujet de la progression notionnelle, de l'évaluation des écrits produits, et des activités et situations (expérimentales et rédactionnelles) à mettre en œuvre.

Nous livrons dans une première partie les informations à caractère scolaire et didactique qui restituent, du point de vue institutionnel, les conditions de l'enseignement obligatoire appliquées à la biologie dans le canton de Genève.

La deuxième partie décrira les productions sélectionnées, pour y chercher des indicateurs langagiers qui renvoient à la stratégie scripturale, à la planification du discours, à la maîtrise lexicale et à l'élaboration conceptuelle. On cherchera notamment à analyser le rôle joué par la « comparaison », en tant que condition même de l'expérimentation et relevant du protocole d'observation (non linguistique), et en tant que niveau de structuration linguistique (énoncé et texte); c'est en quelque sorte une opération commune au raisonnement scientifique et à la formation du discours de savoirs.

Enfin, nous dresserons un rapide bilan des analyses faites, sous 1'angle de corrélations possibles entre la maîtrise langagière et la maturité conceptuelle des scripteurs. Le but est d'alimenter les discussions et collaborations interdisciplinaires, d'orienter en connaissance de cause le point de vue des évaluateurs sur les productions de leurs élèves, et de contribuer à esquisser une conception didactique des écrits de savoirs.

\section{Savoirs et savoir faire visés en biologie : d'une tâche de description simple à des protocoles plus complexes d'expérimentation et de comparaison}

\subsection{Cadre institutionnel et plan d'études de biologie du Cycle d'Orientation (2001)}

Dans les degrés primaires de l'école genevoise, les élèves ont des cours de sciences de la nature. Les cours, de type «naturaliste », se fondent sur l'observation de l'environnement (voir PE de l'enseignement primaire 1E-6P, 2007). Dans le cadre de 1'enseignement secondaire, c'est-à-dire au Cycle d'Orientation (le $\mathrm{CO})$ qui couvre les degrés 7 à 9 (12-15 ans) de l'enseignement obligatoire ${ }^{(2)}$, les élèves suivent des cours de biologie dispensés par des spécialistes. Un plan d'études-cadre - le PECOBIO 2001 - fixe les notions et les démarches à étudier.

(1) Les noms savants sont respectivement le Prunus laurocerasus pour le laurel ou laurier cerise, et l'Ilex aquifolium pour le houx commun. Par ailleurs, précisons que les productions des élèves, constituant les annexes de cet article, figurent intégralement dans la version numérisée de l'article que l'on peut consulter à l'adresse suivante : http://www.pratiques-cresef.fr.

(2) Rappelons à toutes fins utiles que le CO dure 3 ans, contre les 4 du collège français et que par conséquent le «degré » de la $7^{\mathrm{e}}$ vaut pour un niveau $5^{\mathrm{e}}\left(12\right.$ ans) la $8^{\mathrm{e}}$ pour un niveau $4^{\mathrm{e}}$ (13 ans) et que la $9^{\mathrm{e}}$ équivaut à notre niveau $3^{\mathrm{e}}(14 \mathrm{ans})$. La scolarité primaire, qui conduit de la $1^{\text {re }}$ à la $6^{\mathrm{e}}$, présente une année de plus que l'école primaire française. On trouvera par ailleurs, dans la bibliographie de l'article, les références aux plans d'études genevois. 
Les productions écrites présentées et analysées dans cet article ont été réalisées, en 2008, dans des cours de biologie du CO par des élèves de $7^{\mathrm{e}}$ année (regroupement A) et $9^{\mathrm{e}}$ année (regroupements A et B). La partition des regroupements d'élèves en A ou B, importante dans la perspective de ce travail, correspond grossièrement à ce que l'on appellerait en France des filières : les A se destinent à des études ultérieures (1'enseignement post-obligatoire, en France le «lycée » d'enseignement général et technique), les B étant plutôt promis à des filières courtes et professionnelles (nos BEP et « bac professionnel»). On trouve dans le regroupement A les élèves ayant atteint les objectifs minimaux en mathématiques et en français à l'école primaire. Les classes du regroupement B sont composées d'élèves n'ayant pas atteint ces objectifs ni en français ni en mathématiques en $6^{\mathrm{e}}$ primaire, mais qui sont néanmoins promus. Les classes de B sont à effectif réduit, cependant leurs objectifs d'enseignement restent les mêmes que dans le regroupement $\mathrm{A}$. Tout au long des trois ans de $\mathrm{CO}$, les élèves peuvent, en principe, passer d'un regroupement à l'autre en fonction de leurs résultats scolaires.

L'enseignement-apprentissage de la biologie au CO est organisé en unités d'apprentissage construites autour d'un thème ou d'un problème général. L'unité d'apprentissage doit articuler des activités autour de concepts structurants, de notions propres à la biologie et de démarches à généraliser. Elle implique de développer des démarches et des outils spécifiques à la discipline, mais également des démarches transversales. Au titre de ces dernières, nous inscrivons la comparaison. Les concepts structurants généraux (par exemple, «énergie », « équilibre », « espace », «évolution», « fonction »...), directement mis en lien avec les structures du vivant (« cellule », « organe », « système », « individu », « espèce », " écosystème », ou «biosphère »), sont des notions noyaux à partir desquelles on résout certains problèmes de biologie. Quant aux démarches, elles présentent une spécificité d'inspiration «scientifique » (observer, tester, classer) ou au contraire, elles s'appuient sur des compétences qui sont au sens large communicationnelles (décrire, expliquer, argumenter). Ces démarches, conçues comme des compétences socles (Fourez et al., 1997) requièrent à la fois des savoirs spécifiques et des savoir faire métacognitifs (Baker et Brown, 1982, Doudin et Martin, 1992). Les notions et les démarches issues de la biologie créent donc conjointement un réseau de savoirs et de savoir faire, qui excède les frontières du domaine.

\subsection{La place des écrits analysés dans l'enseignement-apprentissage de la biologie}

Les objectifs du plan d'études en biologie supposent une complexité (d'objets et de tâches) qui va croissant, de la $7^{\mathrm{e}}$ à la $9^{\mathrm{e}}$ année. Les productions écrites analysées s'inscrivent dans cette progression, tant au niveau des concepts que des démarches. De même, les écrits produits par les élèves dans le cadre du cours de biologie suivent un ordre de difficulté échelonné.

Le cadre d'apprentissage, qui s'apparente à une approche socio-constructiviste (Bertrand-Renault et Mols, 1999, Fourez et al., 1997), recourt à des situations de construction de savoirs (observation, relation d'expérience, synthèse des résultats) qui visent au plan méthodologique certaines similitudes avec une démarche expérimentale. L'enjeu, au-delà du fait de donner du sens et un but à ce que fait l'élève (ce qu'il découvre, comprend, apprend et communique), consiste à former des esprits scientifiques (rigueur, contrôle et clarté lors des étapes du travail scientifique). Les outils d'évaluation sont ceux de l'évaluation formative (Astolfi et al., 1997b, De Vecchi, 1992), au sens où ils varient selon le rapport moment/fonction de l'évaluation et où les critères sont explicités au mieux. En l'occurrence, les productions 
ont été réalisées en phase certificative, à l'issue d'une séquence d'enseignement, en $7^{\mathrm{e}}$ ou en $9^{\mathrm{e}}$.

L'attention portée aux écrits scientifiques des élèves relève d'une transdisciplinarité qui n'est pas nouvelle. Rappelons que l'enseignement des sciences a volontiers relayé les travaux de la linguistique (Catel 2001), qu'il s'agisse de l'approche communicationnelle (Jacobi 2005), textualiste (Adam 2005) ou discursive (Halté 1988). On avancera, succinctement, que trois problématiques centrales ont occupé le champ : l'analyse des représentations sociales à travers les discours déclaratifs (Lahire 1993), les types et genres d'écrits et leur fonction socio-discursive (Bronckart 1996), et enfin les composantes procédurales de l'écriture (Fayol 1997). Au plan didactique, il faut souligner le rôle institutionnel capital joué en France par l'INRP et la diffusion de deux de ses revues, Repères et Aster, l'une concernant surtout l'enseignement primaire et l'autre l'enseignement des sciences.

L'ensemble de ces travaux de recherche crée les conditions d'une progression didactique en biologie, qui vise conjointement l'élaboration conceptuelle et discursive, inscrivant ses objectifs dans une série graduée de démarches dont le libellé rappelle fortement l'intention sociocognitive et interdisciplinaire : observer, décrire, comparer, expliquer, argumenter.

\subsubsection{Les productions de $7^{e}$ année : de l'observation à la description écrite}

Les productions de $7^{\mathrm{e}}$ année ont été réalisées lors d'une séquence d'apprentissage intitulée «Observation et description du vivant». Cette séquence fait partie de l'unité d'apprentissage «Unité et diversité des êtres vivants 》 (PECOBIO, 2001) qui a comme objectif de découvrir l'unité et la diversité du monde vivant à travers des activités d'observation et de classement. Les compétences mises en œuvre et développées lors de cette séquence combinent l'observation et la description à des fins d'écrit scientifique, les élèves de $7^{\mathrm{e}} \mathrm{n}$ 'ayant encore que peu de pratique dans ces domaines. Même si ces compétences ont été abordées pendant le cycle primaire, le savoir reste en effet largement intuitif et non formalisé.

Joshua et Dupin (2003 : 46-47) soulignent le « primat de la théorie dans l'interprétation de l'observation ». Autrement dit, il n'est pas d'observation innocente, naïve ou spontanée. Observer renvoie nécessairement à des représentations, conscientes ou non, qui, selon le travail notionnel qui les a forgées, guident les perceptions et organisent l'objet perçu en une suite verbale ordonnée. Il en résulte un écrit descriptif qui nomme les différentes parties de l'objet et qui leur attribue des qualités ou des propriétés (longueur, couleur).

Le modèle de référence qui préside à l'organisation du texte descriptif est d'inspiration scientifique, au sens où la dénomination des parties utilise une terminologie de spécialité (pétiole) et où l'écrit adopte une modalité « neutre » ou distanciée, volontiers généralisante. C'est ainsi que les descriptions de rameau que nous présentons (Annexe, D1 à D11) doivent s'interpréter comme des descriptions possibles de tout rameau de laurel ou de houx, quels que soient les accidents particuliers, singuliers, circonstanciels (tache, feuille abîmée, trace de terre, etc.) ${ }^{(3)}$ qui auraient pu marquer telle branche observée. L'observation scientifique s'emploie à noter des propriétés génériques, standardisées et objectives (Fourez et alii,

(3) De ce point de vue, on pourra lire D2, représentatif d'une énonciation très « ancrée »: un peu de terre au dos de la feuille de houx, ou la trace que des bourgeons ont été coupés. De même, D4 signale que sur l'une des feuilles, il y a un petit bout déchiré, deux sur une autre. Enfin, on lira, en D10, une périphrase « inchoactive » pour désigner la présence de bourgeons : «Il y a des petites qui commence à poussées ». 
1997) : le contexte de l'observation fournit des critères « utiles pour la construction d'un modèle approprié ». On remarquera toutefois que, parmi ces critères, la précision «scientifique» a un statut quelque peu ambigu. Que penser par exemple d'une description de rameau qui pousse le soin jusqu'à mesurer au millimètre près la longueur ou la largeur d'une feuille ? L'exactitude de la mesure n'a sa valeur que dans la circonstance du relevé effectué ; c'est «1'ordre de grandeur » approximatif (environ) - la moyenne calculée par comparaison des différentes feuilles mesurées - qui a une validité scientifique. L'observation « filtre » et traite les propriétés, opérant un tri entre des propriétés jugées pertinentes et des traits «parasites ». Se construit ainsi un modèle de reconnaissance empirique, dont les étapes méthodologiques de l'élaboration, l'analyse discriminante, la dénomination des parties et la mémorisation sont guidées par l'observation en classe et l'écrit descriptif. Dans cette perspective, l'interprétation constitue une opération transversale de toute première importance, couvrant l'observation et la description, mais fort difficile à définir et problématiser, théoriquement et didactiquement (Kohn et Nègre 1991 ; Guichard 1998).

Le tableau 1 présente sous la forme d'un extrait synthétique la séquence d'observation. On y vérifiera l'importance de la question lexicale (liste, nomenclature) et le choix d'encadrer le travail des élèves par des aides méthodologiques (outils). À la lecture des textes (D1 à D11), on pourra constater que la recommandation de mesurer en longueur et en largeur, les rameaux et leurs composantes, a été comprise et suivie.

Tableau 1 : séquence d'apprentissage $\left(7^{\mathrm{e}}\right)$ “ Observation et description du vivant" (extrait)

\begin{tabular}{|l|l|}
\hline Objectifs & $\begin{array}{l}\text { - observer le vivant. } \\
- \text { réaliser une description. } \\
- \text { apprendre et utiliser le lexique approprié. }\end{array}$ \\
\hline Activités élèves (1) & $\begin{array}{l}\text { - décrire une branche de lierre ou de buis. } \\
\text { - déterminer l'attitude à avoir pour décrire. } \\
\text { - étude de la fiche-outil " Règles à appliquer pour décrire un être } \\
\text { vivant". } \\
\text { - correction de la description de la branche de lierre, à l'aide de la } \\
\text { fiche-outil et de la nomenclature de la feuille. }\end{array}$ \\
\hline Activités élèves (2) & $\begin{array}{l}\text { - décrire la branche d'un arbre situé autour du collège (consigne : } \\
\text { liste descriptive, document à disposition : fiche-outil et nomencla- } \\
\text { ture de la feuille). } \\
\text { - écrire un texte descriptif à partir de la liste. }\end{array}$ \\
\hline Activités élèves (3) & $\begin{array}{l}\text { - correction de la description de la branche d'arbre à l'aide de la } \\
\text { grille d'évaluation. }\end{array}$ \\
\hline Evaluation certificative & - décrire une branche de houx ou de laurel. \\
\hline
\end{tabular}

\subsubsection{Les productions de $9^{e}$ année : la comparaison d'objets puis de processus}

En $9^{\mathrm{e}}$ année, les comparaisons $(\mathrm{C} 1$ à $\mathrm{C} 13)$ et les rapports d'expérience $(\mathrm{R} 1$ à $\mathrm{R} 13)$ ont été produits dans le cadre commun du thème général « Santé collective et santé individuelle » (PECOBIO, 2001), mais ils s'inscrivent dans deux séquences d'apprentissage distinctes, la première traitant des maladies infectieuses en général, la deuxième construisant une approche expérimentale des bactéries. Les travaux ont été réalisés dans deux classes de $9^{\mathrm{e}}$ année de niveau différent, les regroupements A ou B. 
La comparaison des virus et des bactéries constitue le bilan d'une séquence qui exerçait plus particulièrement la lecture documentaire et scientifique. Les élèves ont travaillé dans une encyclopédie scolaire L'aventure du vivant (Larousse 2006), guidés par les questionnaires de l'enseignante. Le résultat - construction de savoirs - est un écrit comparatif qui a pour but d'évaluer les connaissances des élèves au sujet des bactéries et des virus. C'est ce qu'indique ci-dessous le tableau 2 :

\section{Tableau 2 : Séquence « Les maladies infectueuses » (extrait), $9^{\mathrm{e}} \mathrm{A}$ et B}

\begin{tabular}{|l|l|}
\hline Objectifs & $\begin{array}{l}\text { - Construire les notions d'agents pathogènes et de maladies in- } \\
\text { fectieuses. } \\
\text { - lire et exploiter des textes scientifiques (traiter une information } \\
\text { complexe comprenant du texte, des images, des schémas, des ta- } \\
\text { bleaux, etc.) } \\
\text { - acquérir des notions et des concepts par la lecture. }\end{array}$ \\
\hline Activités élèves & $\begin{array}{l}\text { - lectures de page de } L \text { 'Aventure du vivant. } \\
\text { - réponses aux questionnaires. } \\
\text { - corrections et discussions collectives. } \\
\text { - exploiter un texte résumant avec son questionnaire. }\end{array}$ \\
\hline Evaluation certificative & $\begin{array}{l}\text { - évaluation certificative portant sur les lectures et incluant la } \\
\text { comparaison virus-bactéries. }\end{array}$ \\
\hline
\end{tabular}

On conviendra que l'objet de la comparaison, les virus et les bactéries, ne relève pas d'une « observation » identique à celle qui prévalait en $7^{\mathrm{e}}$ et conduisait à la description de rameaux. L'objet « virus » (ou « bactéries ») est sensiblement plus abstrait, il nécessite une technologie d'observation et il mobilise un savoir scientifique, ce qui le met hors de la portée d'un observateur «naïf » et qui n'aurait que ses yeux pour comprendre. La comparaison renforce la complexité et l'abstraction de la tâche, orientant sensiblement l'analyse vers des procédures de raisonnement. Mais, paradoxalement, la comparaison, activant des critères (taille, fonction, mode de développement, technologie du microscope, etc.) a également pour effet de marquer les étapes de l'observation. La représentation et la formulation de tels critères relèvent de la dimension métacognitive de l'activité, sur son versant «savoirs en biologie » et sur celui, verbal, de l'organisation du texte.

Le rapport d'expérience est une tâche complexe, le texte étant élaboré à partir des notes prises lors de l'expérience. Il est ensuite rédigé à des fins d'évaluation certificative, où sont jugées les connaissances et les compétences acquises lors de la phase d'expérimentation. Le texte a un statut à la fois scientifique (le raisonnement qui sous-tend l'exposé de la démarche expérimentale) et documentaire (l'exactitude des données examinées et de leurs propriétés). On trouvera, dans le tableau 3 (page suivante), une synthèse de ce travail.

On trouvera en annexe de l'article (à l'adresse déjà mentionnée) les productions recueillies, sur lesquelles s'appuient les analyses qu' on va lire. Nous avons pris le parti de consigner en annexe plus de textes que nous ne saurions en étudier dans le cadre de l'article : 11 descriptions, 15 comparaisons ${ }^{(4)}$ et 13 rapports d'expérience. Nous avons souhaité, ce faisant, laisser une certaine autonomie de jugement au lecteur, et, par ailleurs, livrer le corpus nécessaire pour forger des indicateurs.

(4) La numérotation des textes ne suit pas tout à fait la mention de 15 comparaisons; pour des raisons qui sont expliquées en annexe, nous avons parfois recouru à des lettres (par exemple les textes $\mathrm{C} 1 \mathrm{a}$ et $\mathrm{C} 1 \mathrm{~b})$. 
Tableau 3 : Séquence « Les bactéries » (extrait), $9^{\mathrm{e}}$ A et B

\begin{tabular}{|l|l|}
\hline Objectifs & $\begin{array}{l}\text { - imaginer une expérience. } \\
\text { - formuler des hypothèses. } \\
\text { - réaliser l'expérience. } \\
- \text { rédiger un rapport. }\end{array}$ \\
\hline $\begin{array}{l}\text { Activités élèves } \\
\text { par groupe de 2 }\end{array}$ & $\begin{array}{l}\text { - imaginer une expérience. } \\
\text { - formuler des hypothèses. } \\
\text { - transcodage du protocole schématique en texte descriptif. } \\
\text { - réaliser l'expérience. } \\
\text { - Prise de note des résultats et brouillon de rapport. }\end{array}$ \\
\hline $\begin{array}{l}\text { Evaluation certificative } \\
\text { individuelle (A), par 2 (B) }\end{array}$ & $\begin{array}{l}\text { - rédiger un rapport d'expérience à l'aide de la fiche-outil } \\
\text { « Que doit contenir un rapport d'expérience » et de l'ensei- } \\
\text { gnante. }\end{array}$ \\
\hline
\end{tabular}

\section{Productions recueillies : analyse et évaluation. Indicateurs langagiers et savoirs disciplinaires}

Dans cette seconde partie, nous souhaiterions mettre en relation la qualité présumée $^{(5)}$ des écrits recueillis et la stratégie scripturale du producteur avec des indicateurs langagiers. Nous voudrions traiter ces faits de discours sous l'angle des savoirs disciplinaires impliqués et de leur «construction » supposée. Étant donné les dimensions de cet article, nous restreignons notre étude à quelques aspects : la planification du texte, les terminologies et la comparaison. Sans nous interdire absolument des incursions dans d'autres domaines, comme l'orthographe.

La difficulté de l'entreprise réside dans la généralisation du propos et dans son application à d'autres analyses comparables, conduites sur de nouveaux textes. On peut cependant s'accorder sans trop de risque sur le fait que l'entrée lexicale des descriptions, en $7^{\mathrm{e}}$, les marques de comparaison et l'explicitation du raisonnement, en $9^{\mathrm{e}}$, devraient constituer des angles d'analyse intéressants.

Ce faisant, nous souhaitons esquisser les lignes d'une progression dans le développement de la compétence explicative écrite des élèves en situation de restitution de savoir, nous fondant tout particulièrement sur les productions des élèves de $9^{\mathrm{e}} \mathrm{B}$, ou en $7^{\mathrm{e}}$ des copies jugées les plus faibles, pour définir des objectifs-obstacles ${ }^{(6)}$.

Dans les lignes qui suivent, nous avons choisi de traiter chaque famille d'indicateurs en lien avec la série de textes $(D, C$ ou $R$ ) qui les convoque centralement.

\subsection{Les indicateurs lexicaux (série des textes D)}

Pour analyser les descriptions de rameau, il convient de corréler les noms de spécialité aux procédures de thématisation et de planification. Mais nous voudrions auparavant caractériser le vocabulaire des descriptions obtenues.

\subsubsection{Le lexique des descriptions : de la nomenclature spécialisée aux unités lexicales les plus faibles sémantiquement (verbes supports)}

Voici une liste des termes possibles constituant un vocabulaire de spécialité, ou tout au moins dont la forme (un paradigme clos) permet de problématiser la concep-

(5) C'est-à-dire telle qu'elle s'éprouve intuitivement, à la première lecture du texte, chez un correcteur expert, qu'il soit biologiste ou linguiste, pourvu qu'il ait une certaine pratique des textes d'apprenants.

(6) Empiriquement, les enseignants auront reconnu la démarche, courante, qui consiste à évaluer contrastivement, à comparer, dans un paquet de copies, des « copies faibles » avec les copies jugées les meilleures. Une telle confrontation permet de dégager un modèle de réponse et une production standard. 
tion d'une terminologie. Les noms branche, bourgeon, feuille, nervure et rameau redeviennent communs, ou polysémiques ${ }^{(7)}$, dès lors qu'ils ont quitté la série ; nous les faisons figurer ci-dessous ${ }^{(8)}$, sans article et au singulier, comme des notions :

$\begin{array}{lll}\text { Bourgeon } & \text { Foliole } & \text { Pétiole } \\ \text { Branche } & \text { Limbe } & \text { Rameau } \\ \text { Feuille } & \text { Nervure } & \text { Tige }\end{array}$

On remarque la coprésence, dans cette liste, des paires branche et rameau, tige et pétiole, et, dans une moindre mesure, l'équivalence n'étant pas exacte, feuille et foliole $^{(9)}$. Le premier terme est le générique commun du second, spécifique ou terminologique. Notons que nous n'avons pas fait figurer le générique plante, que 1'on trouve pourtant dans les textes D6 et D9.

La disposition des feuilles sur la tige (dans le cas du laurel, les feuilles sont dites alternes), la forme des feuilles, des nervures (principale et latérale) et des découpures (dentée ou pennée) offrent par ailleurs des classes de sous-thématisation ou de prédication qui permettent de compléter l'observation. Il faut y ajouter les propriétés de taille et de couleur, qui sont implicitement construites par comparaison : le dégradé de vert et la comparaison de mesure. Les dimensions et les nuances de vert sont envisagées relativement, les unes par rapport aux autres. On considère ici que disposition, forme, taille et couleur sont des classèmes, autrement dit des unités de sens qui permettent d'appliquer, par différence, des traits qui relèvent d'une même catégorie. C'est ainsi que les mesures particulières, effectuées en longueur et en largeur, sont les traits spécifiques de telle ou telle feuille, regroupés sous le classème « taille ». À cet égard, il importe de remarquer que ces classèmes, probablement essentiels pour la conception de l'objet à décrire, ne relèvent plus d'une nomenclature de spécialité, et sont très inégalement disponibles, d'un locuteur à l'autre. Que l'on compare couleur et taille, par exemple, et l'on conviendra que les discours ordinaires recourent beaucoup plus facilement au premier qu' au second. Pour introduire la « taille » de quelque chose (ou quelqu'un), le français dispose du verbe mesurer.

Après les termes de la nomenclature botaniste (pétiole) et les classèmes génériques (taille), il reste à envisager les verbes supports, les plus faiblement signifiants mais dont la fonction est centrale pour relier un thème à son caractérisant. Cette dernière catégorie, verbale, qui est en quelque sorte une structure d'accueil pour l'expansion prédicative, relève d'une analyse syntaxique. Dans les textes (D), deux verbes très importants remplissent cette fonction : être et avoir. Ils sont à la fois les supports d'expansions lexicalisées et de structures syntaxiques repérées (être d'une couleur...; il y a des $N$ qui...).

Les constructions avec être sont principalement de trois types : être ainsi (Adjectif), être d'une certaine taille (couleur), et, beaucoup plus rare dans notre corpus, la structure locative être quelque part :

- Il est vert clair (D1) - Le bord du limbe est lisse (D3) - Les feuilles sont inégales (D6) ;

- Leur couleur à tous est vert claire (D4) - Elle est d'un vert plus clair que les feuilles (D7) ;

- Les bourgeons qui sont à la base des pétioles sont vert clair (D9).

(7) La nervure par exemple peut intégrer un autre domaine de spécialité (le vocabulaire de la reliure)

(8) À l'exception de pétiolule qui n'est présent (trois occurrences !) que dans un seul texte (D7) et que nous n'avons pas noté.

(9) Feuille et foliole offrent une paire lexicale intéressante, où l'étymologie rejoint une représentation commune, contre la justesse scientifique qui dissocie l'identité référentielle des deux entités. 
Les constructions avec avoir impliquent presque toujours une prédication seconde :

- Le $\mathrm{N}_{1}$ a des $\mathrm{N}_{2}$ (+ expansion) : Elle a 5 feuilles de couleurs vert foncé et 1 pétiol (D8) - Les feuilles ont des nervures vert clair (D9) ;

- Le $\mathrm{N}_{1}$ a un $\mathrm{N}_{2}$ (classème + expansion) : Le pétiole a une forme allongée (D3);

- Il y a Article $_{\text {numéral }} \mathrm{N}$ : Il y a cinq feuilles (D2) - Il y a 5 bourgeons (D4);

- Il y a des $\mathrm{N}$ quelque part : Il y avait 5 bourgeons situés entre le pétiole et le rameau (D2) - En bas de chaque feuille il y a un bourgeons qui mesure 0,3 cm (D5);

-Il y a des N qui présentent telle propriété : Il y a quatres feuilles ovales (D7) - Il y a six bourgeons de couleur vert clair, mesurant $0,5 \mathrm{~cm}$ de largeur (D10) - Il y a des petite qui commence à poussées (D10).

Nous avons surtout voulu mettre l'accent, dans les observations qui précèdent, sur les unités lexicales et les structures dont la fréquence est remarquable. Les éléments relevés sont en effet déterminés par l'objet observé, les objectifs d'enseignement, le genre d'écrit et le lexique-grammaire de la langue française.

En revanche, nous avons sciemment éliminé les emplois fautifs, les jugeant trop peu nombreux et presque anecdotiques dans ce contexte d'une production simple et fortement contrainte, où les parallélismes de construction et les répétitions sont au contraire des garanties de maîtrise (cognitive et langagière).

Pour mémoire, voici des exemples d'erreurs que nous ne développerons pas :

- Orthographe : un peu près (D10); l'accord des adjectifs (tous les textes mais dans des proportions très différentes);

- Lexique : de couleur jaune tourné au vert (D1) - Les feuilles sont accrochées aux pétioles (D7);

- Syntaxe : Il y a des petite qui commence (D10);

- Ponctuation : leurs bourgeons sont brun vert, toutes les nervures verte son rameau est vert, leur longueur est... (D11).

Il reste maintenant à interpréter les occurrences de ces formes dans les textes produits, c'est-à-dire à en faire des indicateurs de réussite.

\subsubsection{Terminologie et planification}

Considérons pour commencer les termes de spécialité énumérés ci-dessus. Trois critères sont a priori exploitables : leur densité (rapport entre le nombre de termes et la longueur du texte), leur exactitude ou pertinence scientifique (pétiole) et leur emplacement dans l'énoncé.

\section{a) La densité et la justesse des termes de spécialité}

Si l'on considère la liste dressée (supra) 9 termes sont possibles, parmi lesquels 3 relèvent d'un vocabulaire commun (branche, tige, feuille).

Les 11 productions d'élèves oscillent entre 6 et 3 noms de spécialité. Les variations sont au plan quantitatif peu signifiantes. Elles le deviennent un peu plus si l'on considère que le texte D1 (6 termes) se dispense des trois termes communs : non seulement branche et tige mais surtoutfeuille ${ }^{(10)}$ également, en sont absents ; et que, inversement, le texte D4 (3 termes) recourt à rameau, bourgeon et feuille. La moindre réussite de D4 est corroborée par la prédication qui s'en tient presque

(10) D1 utilise foliole, mais l'emploi est fautif : «Les folioles mesurent de 12 à $16 \mathrm{~cm}$ ». Il aurait été utile ici de passer par un quantifieur commun comme «la série (ensemble, suite, collection, totalité) des folioles » ; même inapproprié, le nom collectif aurait mieux satisfait la représentation visée. 
exclusivement à des mesures. La décomposition analytique et méthodique de l'objet en ses nervures, limbe, et pétiole est inexistante.

\section{b) L'emplacement du terme dans l'énoncé, dans le texte}

La «conception » de la tâche d'écriture et de sa planification (Fayol 1997) est sensible à travers les titres donnés, dont la diversité est supérieure à celle qu'on aurait pu attendre ; par exemple, Le laurel rond(D1), Description d'un rameau : un laurel (D6), et Laurel (D10) témoignent d'une certaine disparité dans ce qu'on pourrait appeler l'appropriation (cognitive) de la tâche.

Le nom de l'objet à décrire qui figure dans le titre (opération d'ancrage, ou de pré-thématisation, J.-M. Adam $2005: 147$ ) se présente comme un hyperthème dont il s'agit de décliner les parties et leurs propriétés. Les retours à la ligne ou les paragraphes sont le plus souvent corrélés à la thématisation. C'est le cas des textes D2, D3, D6, D7 et D9. D1 et D8 s'en approchent, avec des différences sensibles toutefois. D1 thématise (le rameau, le bourgeon, les folioles...) et planifie (Maintenant la disposition sur le rameau) sur un mode très maîtrisé, chaque sous-thème amorçant un nouvel énoncé ; tandis que $\mathrm{D} 8$ procède selon une progression à thème constant, si l'on peut dire, énumérant chaque feuille dont il donne la mesure (la feuille en bas à droite, la feuille ${ }^{(11)}$ au milieu à droite...).

Deux aspects méritent notre attention : la qualification des thèmes (ou l'attribution de propriétés, Adam 2005: 148) et 1'ordre des sous-thèmes. À cet égard, D3 est très significatif, obéissant à une planification stricte qui permet d'engendrer mécaniquement les énoncés :

- Le $\mathrm{N}_{1}$ a une forme $\mathrm{q}_{1}$, une taille $\mathrm{r}_{1}$ et une couleur $\mathrm{s}_{1}$

- Le $\mathrm{N}_{2}$ a une forme $\mathrm{q}_{2}$, une taille $\mathrm{r}_{2}$ et une couleur $\mathrm{s}_{2}$

- Le $\mathrm{N}_{3}$ a une forme $\mathrm{q}_{3}$, une taille $\mathrm{r}_{3}$ et une couleur $\mathrm{s}_{3}$

$-\ldots$

Une telle solution ${ }^{(12)}$ constitue un savoir faire scriptural non négligeable pour le genre d'écrit demandé ; mais elle peut se révéler être un obstacle dans les situations plus complexes qui sollicitent une résolution de problème.

Quant au critère d'ordre, il nous paraît intéressant à relever parce que c'est le plus implicite. L'indicateur lui correspondant pourrait être la liste brute des noms de spécialité dans l'ordre que le texte leur confère.

À titre d'exemple, voici le résultat pour les textes D2, D8 et D10, choisis pour les difficultés qu'ils manifestent (tableau 4 page suivante).

Le texte D10, qui s'achève sur une sorte de post-thématisation ${ }^{(13)}$ (Adam 2005 : 147), affectant tardivement au texte produit son thème général, est le moins conforme au modèle attendu et soulève des interrogations sur les représentations sous-jacentes et l'organisation des savoirs. La maîtrise, consciente, de ce qui est perçu par l'observateur et de ce qu'il faut en dire - sur quel mode le dire et à quel-

(11) La feuille est un cas d'anaphore fidèle, non coréférentielle.

(12) Nous l'avons identifiée comme «lexicale» et produisant un «effet-liste». Cette stratégie n'est pas très éloignée d'une procédure de copie (Masseron 2005).

(13) Si ce n'est - et c'est important - que le scripteur de D10 ne choisit pas le présentatif c'est (c'est un laurel) mais il y a (il y a un rameau). Cette erreur nous semble symptomatique d'une représentation sémantique (révélée à travers sa «traduction » lexicale) que l'on jugera insuffisamment analytique. À cet égard, on peut rappeler G. Bramaud du Boucheron (1981 : 114) qui décrit le développement des représentations sémantiques, en les fondant notamment sur une évolution conduisant du global à l'analytique, du simple au complexe. L'énoncé de D10 manifeste une représentation sémantique que l'on qualifiera de globale et complexe. 
Tableau 4 : ordre d'apparition des noms de spécialité dans trois descriptions de rameau

\begin{tabular}{|l|l|l|}
\hline D2 (houx) & D8 (houx) & D10 (laurel) \\
\hline Feuilles & Limbe & Feuille \\
Rameau & Feuilles & Bourgeons \\
Pétiole & Pétiole & Tige \\
Bourgeons & & Nervure \\
& & Rameau \\
\hline
\end{tabular}

les fins - est rendue encore plus problématique en raison de la formulation de l'énoncé de clôture : il y a un rameau. Quant à D2 et D8, nous pouvons nous demander si la densité moindre des noms de spécialité n'est pas due à la complexité moindre de l'objet référentiel (la feuille de houx comme objet du monde).

\subsection{Les marques de comparaison (série des textes $\mathrm{C}$ )}

Même si ce sont principalement les textes de la série C qui comportent des comparaisons, la comparaison n'est pas absente des deux autres séries. C'est ainsi que D6 et D7 présentent des comparaisons, locales, dont les marques sont énumérées ci-dessous :

- Une propriété apparentée à une différence et marquée lexicalement : Les feuilles sont inégales ; elles ont toutes des mesures différantes; elles (les nervures) ne sont pas de même longueur (D6);

- La structure comparative en plus, moins, autant : elle est d'un vert plus clair que les feuilles (D7);

- L'emploi de comme : ...verts comme le pétiole (D7).

Notons, à un plan intermédiaire, qui engage la cohésion des enchaînements d'énoncés, l'existence d'adverbes de planification du type de aussi ou également, qui signalent que l'énoncé ajouté vient compléter une énumération commencée, sur la base d'une prédication comparable à la précédente. Les prédications se rapprochent pour l'intention visée (l'ajout d'un sous-thème) et/ou pour la propriété décrite : la différence ne concerne que l'entité « tout » dans son rapport à la "partie » que prédique l'énoncé. D7 présente les deux cas :

- Il y a aussi des points bruns (D7) : le tout est ici le pétiole ;

- Il y a également quatres bourgeons (D7) : le tout est plutôt le rameau, les bourgeons n'étant plus partie intégrante du pétiole, mais dans une relation de proximité spatiale.

Quant à la comparaison, envisagée comme une opération guidant la planification, à un niveau de structuration globale de la séquence de discours, nous en avons des illustrations variées avec la série des textes C. Les marques combinent plusieurs domaines : la ponctuation (la disposition des paragraphes), la syntaxe (les constructions parallèles ou elliptiques; les reprises pronominales du sujet : la bactérie, elle,...) et le lexique (les connecteurs contrastifs : mais, par contre; les connecteurs d'énoncés adjoints : alors que, tandis que).

Les exemples qui viennent d'être mentionnés attestent que la comparaison d'une part se réalise par des marques variées, et d'autre part, qu'elle contribue à structurer des unités de discours de dimension variable, du syntagme à la période, voire la séquence. C'est cette diversité de formes et de fonctions de la comparaison qui, nous l'avons dit, a attiré notre attention sur les phénomènes engagés. Ce sont les hypothèses de travail interdisciplinaires que nous avons ébauchées à Genève, 
dans le cadre d'un groupe de formation-recherche qui avait vocation à réfléchir sur les compétences transversales à l'œuvre dans les situations d'écriture scolaire ${ }^{(14)}$. Nous citerons ci-dessous quelques extraits du plan d'études qui reprend les conclusions du groupe cité.

\subsubsection{Hypothèse de travail : la comparaison, un outil d'activités transversales}

Dans ses dernières pages, le texte d'application du plan d'études pour le Français (2009) développe à titre exploratoire des hypothèses de travail sur la comparaison. Voici les différentes thématiques de ces « hypothèses », inégalement rédigées ${ }^{(15)}$; elles occupent 11 sous-parties, du cadre général à l'analyse circonstanciée des capacités mises en œuvre et des composants d'une comparaison ; ci-dessous, nous citons les points qui se rapportent plus directement à la comparaison des bactéries et des virus, dans les productions des élèves (les hypothèses 5 et 6 tout particulièrement) :

\section{Hypothèses générales du travail : rappel des principales structures comparatives et obstacles supposés à une démarche de comparaison (en production d'écrit)}

1. Savoir comparer est une compétence discursive et cognitive, mobilisée notamment dans tous les domaines disciplinaires qui s'appuient sur des « textes » et qui ont pour objectif général d'étoffer les connaissances encyclopédiques des élèves tout en renforçant leurs aptitudes à l'observation et à l'analyse.

2. La comparaison, si l'on se rapporte à son origine rhétorique, est à la fois figure de mots ( $x$ est comme y) et figure de discours (c'est comme quand...). Dans un cas, elle tend à se rapprocher de la métaphore (cet âne de Dupont) et dans l'autre de l'analogie (raisonnement par analogie : l'orthographe c'est comme une cathédrale... elle mérite les mêmes soins de conservation.).

3. Le traitement syntaxique de la comparaison [...]

4. Le traitement lexical de la comparaison [...]

5. La comparaison comme opération de traitement intellectif, si l'on convient qu'elle vise à faire comprendre les ressemblances et différences de traits entre deux objets, est, de façon quasi-prototypique, symbolisable par un tableau à double entrée. Mieux que tout autre représentation, le tableau à double entrée associe synthèse et analyse, suscite des comparaisons spécifiques (les différentes fenêtres du tableau), globales (les deux colonnes du tableau identifiées par les deux objets comparés), ou de rang intermédiaire (la spécification d'un seul critère, dont l'entrée équivaut à une ligne).

6. La comparaison en tant que raisonnement, support d'une opération rédactionnelle, présente la difficulté particulière de devoir traiter simultanément deux objets thématiques et non un seul. Il s'ensuit une alternative que l'on peut résumer ainsi :

(14) Les participants à ce groupe, dont les travaux ont duré deux ans (2006-2008), ont été respectivement Alain Seiler, Bernard Pinget, Wagih Azzam, Élodie Urbina et Anne Von Burg pour le français, Soledad Valera Kummer et Alessandro Conti pour la biologie, Fabienne Payré et Françoise Luisier pour l'histoire. Les travaux effectués dans les classes de ces collègues ont alimenté les séances de travail et finalement conduit à une première synthèse écrite, sous la forme d'une annexe consignée dans le guide méthodologique du Plan d'études genevois pour le français et dont la rédaction a été faite par Caroline Masseron (2009: 78-86). Le présent article cite et prolonge ce travail. L'occasion nous est offerte de remercier très chaleureusement les collègues qui se sont engagés sans mesure dans un projet dont ils savaient par avance ne rien devoir attendre comme effets pratiques immédiats.

(15) Dans quelques cas, le texte présente des comparaisons issues de textes d'auteurs ou d'apprentis scripteurs. Dans d'autres cas, au contraire, l'hypothèse est énoncée dans sa forme la plus générale. 
a) soit on traite séparément et successivement chacun des deux objets ; b) soit on réunit les deux objets au moins pour commencer, et l'on isole ou dissocie les aspects (ou critères) sur lesquels on les compare. Dans le premier cas (écriture à plan), on risque de perdre le fil rédactionnel au profit d'une description approfondie et détaillée du premier objet puis du second, livrant ainsi des unités de texte certes analytiques mais trop autonomes. La planification du propos peut se réduire à une simple énumération, dont les liens de cohésion entre les énoncés peuvent se révéler assez sommaires (lâches). Dans le second cas (écriture à processus), il faut impérativement que le scripteur ait identifié (c'est-à-dire nommé, consciemment) un ou plusieurs critères de comparaison pour regrouper les propriétés des objets, tout en les dissociant. Le coût cognitif et l'habileté rédactionnelle paraissent d'une exigence bien supérieure avec cette deuxième solution.

7. Les domaines de spécialité convoqués et les oppositions objet simple / objet complexe et concret / abstrait $[\ldots]^{(16)}$

8. Les usages sociaux (non scolaires) et oraux de la comparaison (dans des situations de choix ou d'hésitation) [...]

9. Le rang structurel ou sémiotique des comparaisons dans différents textes ${ }^{(17)}$ $[\ldots]$

10. Schématisation et terminologie [...]. Objets comparés, motif de comparaison et prédication (développement différenciateur). [...]

11. Activités d'écriture : produire des comparaisons.

Nous pouvons figurer la comparaison des virus et des bactéries, demandée aux élèves de $9 \mathrm{~A}$ et $9 \mathrm{~B}$, sous la forme d'un tableau à double entrée, ainsi que le suggère l'hypothèse 5 rappelée ci-dessus. Le cadre du tableau - c'est-à-dire le support de l'activité de comparaison - se présente ainsi :

Tableau 5 : cadre de comparaison pour différencier les virus et les bactéries

\begin{tabular}{|l|l|l|}
\hline Critères & Bactéries & Virus \\
\hline Taille & & \\
\hline Observation & & \\
\hline Composition & & \\
\hline Matériel génétique & & \\
\hline Reproduction & & \\
\hline Traitement & & \\
\hline
\end{tabular}

Le tableau, une fois renseigné, donne ceci :

(16) Voici un exemple de sujet d'examen donné en L (2008) qui sollicite un traitement comparatif : "Expliquez pourquoi dans la conjugaison française les marques graphiques des personnes dites du singulier sont plus difficiles à acquérir que celles du pluriel. »

(17) Les comparaisons, en contexte scolaire, sont des textes brefs, ainsi qu'en témoigne notre corpus C. Il en va autrement des comparaisons que nous lisons dans des ouvrages plus « savants ». C'est pour illustrer ces usages experts (et complexes) que quatre extraits sont cités et sommairement analysés; en l'occurrence, il s'agit d'une analyse sociologique (Pinçon et Pinçon-Charlot 2003 La chasse à courre, Petite Bibliothèque Payot), d'un fragment d'histoire médiévale (Marc Bloch, La société féodale, 1939), d'un discours de vulgarisation anthropologique sur les systèmes d'écriture (Jaffré et Fayol, 1997, Orthographes, des systèmes aux usages, Flammarion Dominos) et d'un texte qui donne le cadre juridique de l'histoire des déclarations de droits de 1'homme (Lucien Jaume, 1989, Les déclarations des droits de l'homme, GF Flammarion). 
Tableau 6 : comparaison entre les virus et les bactéries

\begin{tabular}{|l|l|l|}
\hline & Bactéries & Virus \\
\hline Taille & $2 \mu \mathrm{m}$ & 200 à $300 \mathrm{~nm}$ \\
\hline Observation & Microscope optique & Microscope électronique \\
\hline Composition & $\begin{array}{l}\text { Unicellulaires : n'ont pas de } \\
\text { véritable noyau }\end{array}$ & $\begin{array}{l}\text { Ne sont pas des cellules : } \\
\text { composés d'une capside (où est } \\
\text { une molécule qui porte les } \\
\text { informations génétiques) }\end{array}$ \\
\hline Matériel génétique & ADN & Soit ADN soit ARN \\
\hline Reproduction & Autonomie (milieu propice) & $\begin{array}{l}\text { Pas d'autonomie : dépendent de } \\
\text { la cellule hôte }\end{array}$ \\
\hline Traitement & Antibiotique & Vaccin \\
\hline
\end{tabular}

Grâce à ce dernier tableau complété, on peut vérifier l'ordre, la complétude et la justesse des informations livrées par les textes des élèves. Au-delà de sa fonction de contrôle, il faut toutefois considérer que le tableau à double entrée, réglé par un ordonnancement uniforme (les fenêtres sont toutes remplies), est parfois trompeur. Les critères n'y sont pas toujours équivalents, ni en complexité (taille et composition, par exemple), ni en pertinence (observation et reproduction) ; et l'objectivité scientifique affichée n'est pas moins illusoire : l'information donnée est sélectionnée et répond à une visée argumentative générale (santé et société) dont on retrouve d'ailleurs la trace dans quelques productions d'élèves.

Mais surtout, la mise en discours des informations contenues dans le tableau est, au plan des capacités scripturales requises, une opération de transcodage complexe. Il suffit, pour s'en convaincre, d'identifier, dans la série des quinze textes C recueillis, les productions qui se rapprochent ou au contraire s'éloignent le plus du tableau 6. L'indicateur de la mise en paragraphes est sans doute le premier qu'utiliserait tout évaluateur.

\subsubsection{La planification des comparaisons : paragraphes et stratégies scripturales}

Les textes C7, C9 et C10 pour la classe de 9A sont très représentatifs d'une planification qui est non seulement contrôlée mais montrée. La rhétorique la plus aboutie est illustrée par C10. Nous soulignons (ci-dessous, en italique) les indices d'une mise en texte coopérative, manifestant que le scripteur maîtrise la dimension particulière de l'interaction scolaire. Nous marquons également (en gras, cidessous) le critère de comparaison dont la position dans l'énoncé est signifiante, suivant immédiatement l'expression de planification :

C10 Si nous comparons les virus et les bactéries nous pouvons parler de leur taille, leur façont de se reproduire, la manière de les observer et où, leur matériels génétiques et sous quelle forme nous pouvons les rencontrer.

Commençons tout d'abord par leur taille, les virus font environ 200 à $300 \mathrm{~nm}$, tandis que les bactéries font $300 \mu \mathrm{m}$. Ensuite parlons de leur façont de se reproduire. Les bactéries se reproduisent d'elles mêmes pourvu que l'endroit leur soit propice, contrairement aux virus qui eu ont besoin des cellules de notre corps mais attention seulement celles qu'elles veulent attaquer.

Continuons avec la manière de les regarder et où. Les virus ce regardent au microscope électronique mais pas les bactéries qui elles ce regardent au microscope optique et nous pouvons les observer avec ces instruments en laboratoire. Par ailleur, si nous parlons de leur matériels génétiques, nous pouvons constater que les virus on de l'ADN et de l'ARN et que se sont des sortes de capsides et que les bactéries, elles 
ne contiennent que de l'ADN et qu'elles sont des unicellulaires. Pour finir, nous pouvons rencontrer les virus sous plusieurs forment différentes cela dépent des maladies mais par contre les bactéries on toujour la même forme et sont des mécanismes autonomes, au-lieu des virus qui sont des métabolismes inertes.

La planification de C9, par contraste, est moins sophistiquée et frappe par sa compacité thématique : un paragraphe pour le virus, un paragraphe pour la bactérie. La rédaction du second paragraphe se fait sur un mode plutôt linéaire, et surtout dynamique et contrastif, voire symétrique (l'ordre des critères s'inverse quasiment « en miroir»). En effet, dans C9, le paragraphe «bactérie » témoigne de la rédaction précédente du paragraphe « virus », ce dont atteste, entre autres, la longueur moindre du second paragraphe. Le scripteur maîtrise le rôle joué par la mémoire du discours antérieur. Voici l'extrait de C9 concerné par ces mécanismes de dynamicité interne (nous soulignons) :

C9 C'est une des raisons pour laquelle, tous les chercheurs ne sont pas d'accord sur le fait que ce [= le virus] soit un être vivant.

Pour la bactérie, les chercheurs sont d'accord, c'est un être vivant donc elle peut se reproduire toute seul. Elle ne peut être composé que d'ADN et n'a qu'une seule cellule. Sa taille est de $2 \mu \mathrm{m}$. Elle a toujours une forme à peu près ovale. Quand à l'outil que l'on doit utiliser pour l'observer, c'est le microscope obtique.

Notre troisième exemple d'une planification contrôlée, C7, offre l'intérêt d'une stratégie scripturale qui se rapproche du paradigme ou de la liste : répétition des tours syntaxiques, fréquence des retours à la ligne, et sous-thématisation de l'énoncé qui procède toujours dans le même ordre : d'abord le virus, puis la bactérie. C7 manifeste, avec réussite, ce que peut être une stratégie scripturale à dominante «lexicale» (l'effet-liste, le texte obtenu par « copie», Masseron 2005). Voici C7 :

C7 Comparaisons entre virus et bactérie

Le virus est composé de matériel génétique ADN ou alors ARN, tandis que la bactérie a comme matériel génétique seulement l'ADN.

Le virus a plusieurs formes, tandis que la bactérie, elle, a une forme unique.

La possibilité de reproduction n'est pas la même. Effectivement, le virus a besoin de la machinerie de reproduction de la cellule hôte, alors que la bactérie peut se reproduire sans l'aide d'une autre cellule. Le virus n'a pas de métabolisme.

Les traitements ne sont non-plus pas les mêmes. En effet un virus se traite avec des antiviraux ou bien alors avec des vaccins, tandis que la bactérie se traite avec des antibiotiques.

Finalement, la taille de ces deux agents pathogènes n'est pas la même. Le virus mesure 200 à $300 \mathrm{~nm}$, alors que la bactérie mesure $2000 \mathrm{~nm}$. Ce qui revient à 10 fois plus grand que le virus.

Pour compléter ces exemples de planification, il convient de signaler C8: le texte est en un seul paragraphe, mais y sont soulignés le titre et les critères de comparaison. La densité des informations, concentrées en peu de mots, renvoie à une stratégie scripturale à dominante "sémantique " et l'effet-résumé qui en résulte, à la lecture. La planification de C8 est linéaire et le soulignement - réalisé sans doute a posteriori - réintroduit le paradigme des critères que d'autres scripteurs traitent avec les retours à la ligne. Voici C8 :

C8 La differance entre les bacteries et les virus

Les bacterie et les virus n'ont pas la même taille, un virus est plus petit, on peut le voir qu'au microscope electronique tandis que la bacterie peut être vue au microscope optique. leurs materiel génétique n'est pas le le même. une bacterie contient 
de l'ADN tandis que le virus contient de l'ARN et de l'ADN. leurs formes n'est pas la même, une bacterie est une seule cellule donc elle est ronde tandis que chaque virus est different. les bacteries se reproduisent seules, les virus, en revanche, on besoin d'une cellule hôte. les moyens pour lutter contre les virus sont le vaccins et les antiviraux, contre les bacteries, les antibiothique sont le moyen de lutte.

À envisager ainsi les productions, sur un « continuum » qui conduit des textes les plus structurés à ceux dont la planification relève d'un enchaînement linéaire et plus local, nous citerons, pour compléter cet aperçu, le texte C11. Nous y faisons figurer en italique les indices d'une stratégie à visée " pragmatique », assez nettement marquée par l'effet-dialogue, autrement dit par l'instauration d'un traitement polémique de la comparaison (les prédications de propriétés sont envisagées comme des arguments) et par des marques d'oralité ${ }^{(18)}$ (les énoncés, brefs, sont construits autour des noyaux verbaux et les tours négatifs s'appuient sur une ellipse) :

\section{C11 Compare un virus et une bactérie}

Le virus n'est pas une cellule, mais par contre la bactérie oui. Le virus s'attaque à une cellule precise dite cellule hote, mais pas la bactérie. Le virus se developpe dans la cellule hôte, tandis que la bactérie pas. Et aussi le virus ce reprodui dans la cellule hôte, pas comme les bactéries. En suite la cellule hôte meure a cause du virus.

Le texte qu'on vient de lire est très lacunaire si l'on rapporte les informations qu'il restitue à celles du tableau 6 . C'est le résultat de ce point de vue polémique : les propriétés de la bactérie sont envisagées par différence et secondairement, c'est-à-dire relativement à celles du virus. Le virus est le sujet de topicalisation de chaque énoncé et, finalement donc, du texte. Cet éclairage (par le virus) se manifeste par le fait que la quasi-totalité du texte se consacre au récit biologique de la transformation conjointe du virus et de la cellule hôte (le virus s'attaque, se développe, se reproduit; la cellule meurt). C11 tient à la fois de l'argumentation et du récit, sans être seulement l'un ou l'autre, et minore les données plus " objectives» et « statiques" qui sont la trace du savoir scolaire à restituer.

Les comparaisons produites par les scripteurs de 9B sont sensiblement moins planifiées. Non pas que les paragraphes en soient absents mais le contenu s'y révèle moins organisé. Deux options se dégagent, étayant ce que nous avancions dans notre hypothèse 6 (supra) : soit le virus et la bactérie sont les entrées thématiques de deux paragraphes successifs (C1a, C5); soit l'objet de la comparaison et le motif occupent tour à tour la position thématique, sans qu'un principe d'ordonnancement se dégage clairement (C3, C4a, C4b). Le scripteur doit affronter l'existence de deux objets (virus et bactérie) et la variété des motifs de comparaison. Certains textes traduisent cet embarras et une gestion " pas à pas » de l'activité rédactionnelle par des dislocations pronominales et par le recours à pour, tours qui facilitent la réorientation thématique. Par exemple (nous soulignons) :

- C3 : Les virus nous les traitons avec un vaccin

- C4a : Entre un virus et une bactérie leur traitement est différent, le virus pour le combattre est le vaccin, la bactérie pour le soigné ou le combattre est l'antibiotique. Ils ne sont pas visible à l'œuil nu, pour le virus il faut l'observer au microscope éléctronique, la bactérie il faut l'observer au microscope optique.

- $\mathrm{C} 4 \mathrm{~b}$ : les virus mesurent environ $2 \mu \mathrm{m}$ et peuvent se voir au microscope optique, les bactéries, celles-ci, mesurent

Plus généralement, les indicateurs langagiers d'une fragilité structurelle ren-

(18) $C f$. plus haut, notre hypothèse 8 . 
voient à des phénomènes de gestion thématique, de pronoms et de ponctuation, et les solutions trouvées rappellent les tours conversationnels de l'oral. L'obstacle rencontré par ces scripteurs rend compte d'une sorte de belligérance phrase/texte non résolue, ce que nous évoquions supra dans notre hypothèse 9 au sujet du rang sémiotique de la comparaison. La difficulté est autant langagière que cognitive, comme en témoigne le texte $\mathrm{C} 1 \mathrm{~b}$ (nous soulignons) :

La taille du virus et de la bactéries ne sont pas les mêmes, le virus est plus petit que la bactéries. Le virus se soigne avec les vaccins, et les bactéries peuvent se soigner naturellement ou avec des antibiothiques. Et ils ne donnent pas les mêmes sympthomes. Ils ne s'attrapent pas pareils, et se nourisse différeamment.

En C1b, les différences sont énoncées «globalement», selon un mode non analytique. Le scripteur paraît démuni devant les ressources lexicales qui nommeraient spécifiquement la nature de la différence invoquée. De ce fait, il énonce en position finale (rhématique), un prédicat commun de « différence », se contentant d'en varier la forme lexicale (pas les mêmes, pas pareils, différemment). L'association d'une difficulté cognitive et d'une faiblesse langagière est illustrée par les erreurs morphosyntaxiques du premier énoncé :

La taille $d u$ virus et de la bactéries ne sont pas les mêmes.

On peut supposer que si le générique « agent pathogène » avait été disponible, l'attaque du texte aurait pu éviter l'entrée par un trait particulier d'importance moindre (" le virus et la bactérie sont deux agents pathogènes qui se distinguent par un ensemble de traits, dont par exemple la taille et le traitement pour les combattre »). Il y a en quelque sorte collusion « syncrétique » entre les objets à comparer, le motif de comparaison et les différences qui résultent de l'opération.

Pour conclure cette partie sur la planification d'une comparaison, mentionnons le texte $\mathrm{C} 3$, qui est remarquable par son absence de ponctuation :

C3 Les virus nous les traitons avec un vaccin et les bactéries avec les antibiotique on regarde les virus avec le Microscope electronique et les bactéri avec un Microscope optique les virus son former de plusieur cellul et les bacterie son des unicellulaire les virus provoque des maladies virals et les bacterie provoque des maladie bacterienne

L'absence de ponctuation est compensée par le parallélisme syntaxique (par exemple, avec, avec ; provoque, provoque, etc.). Par ailleurs on relève qu'un mécanisme de cohésion est marqué par et, permettant d'introduire localement et minimalement le thème «bactérie » sur le mode contrastif qui est demandé, à la suite du thème « virus ».

\subsubsection{Le traitement "syntaxique " de la comparaison: la présence ou}

l'absence de tandis que

L'auteur du texte que nous venons de présenter (C3) abuse de la polysémie de et ; l'effort économisé lors de l'encodage a sa contrepartie et coûte un certain prix, à la réception du texte. $\mathrm{C} 3$ se voit privé d'un connecteur comme tandis que, dont l'apport sémantique aurait pu contribuer au confort de la lecture. La présence ou l'absence de tandis que dans les textes $\mathrm{C}$ semble être un indicateur non négligeable, en fréquence et en qualité sémantique, de la maîtrise rédactionnelle et notionnelle d'une tâche de comparaison telle que celle-ci.

De fait, un seul texte, C9, sur les 8 disponibles en provenance de la classe de 9A, n'emploie pas le connecteur tandis que. L'explication concernant cette absence dans C9 est assez simple : le texte distribue la matière informative en deux para- 
graphes bien distincts (le virus, la bactérie) et n'a pas besoin de marquer par un connecteur le contraste de la seconde prédication. Le deuxième paragraphe se lit par référence au premier, ainsi que nous l'avons déjà signalé. Les autres comparaisons produites en 9A non seulement utilisent tandis que, mais l'utilisent plusieurs fois, et la plupart du temps pour introduire le deuxième segment de la comparaison $^{(19)}$; de surcroît les textes préfèrent tandis que à alors que ${ }^{(20)}$. Une telle régularité, si elle devait se confirmer comme un indice de réussite, mérite attention.

Les textes de la série produite en 9B ne présentent apparemment pas une distribution aussi régulière et fréquente, pourquoi ? Posée ainsi, la question ne doit pas entraîner de malentendu. Il ne s'agit pas de porter un jugement de « pauvreté syntaxique » sur une copie privée du connecteur, mais de repérer ce qui tient lieu d'outil de connexion. Par quoi est suppléé tandis que, quand celui-ci est absent? En quoi tandis que serait susceptible de renforcer la cohésion et la coopérativité du texte? Dans le tableau 7, nous synthétisons le relevé des occurrences de tandis que et, quand il y a lieu, des outils complémentaires, lesquels sont tantôt des connecteurs pragmatiques, tantôt des faits de ponctuation.

Tableau 7 : tandis que dans les textes $\mathrm{C}$, répartition selon les deux classes (9A et 9B)

\begin{tabular}{|c|c|c|}
\hline & 9A (8 textes) & 9B \\
\hline \multirow[t]{7}{*}{ Tandis que } & $\begin{array}{l}\text { C6 }: 1 \text { occurrence en tête de } \mathrm{P} \\
\text { Par contre } \\
\text { Mais contrastif }\end{array}$ & C2: 1 occurrence \\
\hline & $\begin{array}{l}\text { C7 : } 3 \text { occurrences } \\
\text { Alors que, } 2 \text { occurrences }\end{array}$ & C4b : 1 occurrence en tête de $P$ \\
\hline & $\begin{array}{l}\mathrm{C} 8: 3 \text { occurrences } \\
\text { En revanche }\end{array}$ & \\
\hline & $\begin{array}{l}\text { C10 : } 1 \text { occurrence } \\
\text { Contrairement à } \\
\text { Mais par contre } \\
\text { Mais pas } \\
\end{array}$ & \\
\hline & $\begin{array}{l}\text { C11 : } 1 \text { occurrence } \\
\text { Mais pas } \\
\text { Pas comme } \\
\end{array}$ & \\
\hline & C12: 4 occurrences & \\
\hline & C13: 1 occurrence (P graphique) & \\
\hline \multirow[t]{5}{*}{$\varnothing$} & C9: deux paragraphes thématiques & C1a : mise en paragraphes \\
\hline & & $\mathrm{C} 1 \mathrm{~b}:$ et \\
\hline & & $\mathrm{C} 3: e t$ \\
\hline & & $\begin{array}{l}\text { C4a : dislocation à l'aide de pour } \\
\text { Mais, et }\end{array}$ \\
\hline & & C5 : mais \\
\hline
\end{tabular}

Ce que nous appelons «P graphique » dans le tableau signifie que l'énoncé introduit par le connecteur tandis que est un énoncé délimité graphiquement comme une «phrase simple».

(19) Le texte qui fait exception est C6 : Tandis que $P$ y figure en position initiale. En 9B, on trouve $\mathrm{C} 4 \mathrm{~b}$.

(20) Dans la série produite par les élèves de 9A, C7 utilise les deux connecteurs, dans une alternance assez scolaire, qui rappelle la consigne d'éviter les répétitions. 
Essayons de tirer les enseignements des relevés. Les productions sinon les plus réussies au moins les plus efficientes sont celles qui n'hésitent pas à reconduire le même moule syntaxique : ordre des thèmes et réitération de tandis que. C 8 est le prototype d'une telle routine syntaxique, maîtrisée et performante. À l'inverse, un texte comme C4a, s'il manifeste le besoin de s'appuyer sur des structures parallèles, son auteur en revanche ne dispose pas des ressources langagières nécessaires pour l'enchaînement et la cohésion des énoncés. Le texte manque du lien cohésif propre au genre d'écrit pour lequel il est sollicité (exposition méthodique et critériée de savoirs en biologie). La ressource d'un cadre syntaxique, intuitif et importé d'une pratique langagière spontanée, n'est plus suffisante ici, ainsi qu'en témoignent les effets de rupture ou de continuité, gérés au coup par coup : délimitation hasardeuse des paragraphes, ponctuation (la virgule tient lieu de point), anaphores, valeur référentielle du pluriel, détachement et extraction d'un sous-thème à l'aide de pour, distribution de et et mais (nous soulignons) :

$\mathrm{C} 4 \mathrm{a}$. Entre un virus et une bactérie leur traitement est différent, le virus pour le combattre est le vaccin, la bactérie pour le soigné ou le combattre est l'antibiotique. Ils ne sont pas visible à l'œuil nu, pour le virus il faut l'observer au microscope éléctronique, la bactérie il faut l'observer au microscope optique. Leur taille sont assez différente le virus mesure 200-300 nanomètre et la bactérie mesure $2 \mathrm{um} \Rightarrow 2000$ nanomètre.

Le virus n'a pas de cellules mais il contient du capside de protéine, la bactérie est unicellulaire elle a juste une cellule et la forme du virus est multiples mais pour la bactéries elle est ovales.

Un énoncé de C4a, « la bactérie pour le soigner ou le combattre est l'antibiotique », nous paraît représentatif des effets de continuité et rupture que nous voulons signaler. Le sous-codage syntaxique (Gross et Prandi 2004 : 31-32) s'accompagne d'un enchaînement lexical vaguement synonymique (soigner et combattre) et rendu fautif par le suivi anaphorique (le) dont la source référentielle n'est pas la même (soigner le malade ou la maladie bactérienne; combattre la bactérie ou la maladie). L'emploi erroné du verbe être dans l'énoncé relève également d'une approximation assez comparable : on $a \Rightarrow=i l$ y $a \Rightarrow c$ 'est $\Rightarrow$ est l'antibiotique.

Nous ne saurions terminer cet aperçu sur les moyens langagiers mis en œuvre pour écrire une comparaison sans évoquer plus spécialement le connecteur tandis $q u e$. Notre intérêt pour ce connecteur est, rappelons-le, dicté par le fait que les productions les plus réussies l'utilisent à bon escient et plusieurs fois dans le même texte. On peut postuler que c'est l'intuition langagière des élèves concernés qui les guide judicieusement dans le choix de ce connecteur, et non pas une quelconque contrainte professorale explicite ${ }^{(21)}$.

Le connecteur tandis que a été notamment étudié par Guimier (2000), dans un article où tandis que est opposé à alors que. La notion de "congruence » est identifiée comme la valeur modale qui établit une frontière sémantique entre les deux connecteurs et explique partiellement la répartition des emplois. Alors que signale, outre sa valeur temporelle, des emplois non-congruents, tandis que des emplois congruents. Précisons sommairement que Guimier entend par non-congruence un effet de discordance, de décalage ou de non-validation d'une norme, qui relie, avec alors que, les contenus propositionnels. La contrastivité (l'adver-

(21) Ce serait plutôt dans le cadre du cours et des manuels de français (et non pas de biologie) que l'on rencontrerait l'injonction de faire usage de tel ou tel connecteur. Il n'est pas exclu évidemment que les élèves de cette classe de 9 A aient suivi un enseignement sur la valeur et l'usage des connecteurs, auquel cas les textes produits dans le cadre de la biologie montrent que le transfert s'est opéré. 
sativité) du connecteur se voit ainsi précisée. La congruence de tandis que traduirait au contraire un contraste à valeur téléonomique (Guimier 2000 : 105) : les deux propositions sont les deux facettes, complémentaires, parallèles, d'une même question, et sont reliées, conformément à l'étymologie du connecteur (aussi longtemps que; le comparatif d'égalité), à une norme de comparaison validée. Guimier rappelle 1'étymologie en ces termes : «On peut faire l'hypothèse que tandis que a gardé certaines des propriétés du comparatif qu'il est originellement. Tout d'abord, la proposition P est partout et toujours le terme comparé (l'élément repéré) et la proposition $\mathrm{Q}$ le terme comparant (1'élément repère). La relation $\mathrm{P} / \mathrm{Q}$ n'est donc pas symétrique. » (Guimier 2000 : 102).

La visée téléonomique signifie qu'une même « échelle orientée » sert de cadre à la relation : « [...] les contenus propositionnels de P et Q sont coorientés. En un mot, les procès de $\mathrm{P}$ et de $\mathrm{Q}$ vont dans le même sens », ainsi que l'écrit Guimier, citant Rivara (1990). L'étude spécifie la complémentarité ou le contraste comme valeurs particulières de la congruence. Le contraste est envisagé, sous l'effet de tandis que, comme "opérant au sein d'un ensemble. (P et Q) sont les deux facettes d'un tout, et, s'il y a contraste entre P et Q, il y a surtout complémentarité. L'une des deux propositions n'invalide pas l'autre, aux yeux de l'énonciateur, lequel les assume pleinement toutes les deux, comme il assume le contraste entre P et Q. La valeur de contraste est donc présente avec celle de complémentarité. Même lorsqu'une altérité forte est marquée, tandis que souligne que cette altérité est en quelque sorte conforme à une norme et donc attendue. " (Guimier 2000 : 108).

Voici un échantillon d'énoncés comportant tandis que, qui nous permettra de saisir pratiquement l'analyse de Guimier :

C2. Les virus sont différent des bactéries parce qu'ils se soigne avec un vaccin tendi que les bactéries se soigne avec un antibiotiques.

C7. Le virus est composé de matériel génétique $\mathrm{ADN}$ ou alors $\mathrm{ARN}$, tandis que la bactérie a comme matériel génétique seulement l'ADN.

C11. Le virus se developpe dans la cellule hôte, tandis que la bactérie pas.

C6. Tandis qu'on peut observer les bactéries avec des microscopes optique, il faut observer les virus avec des microscopes électronique. De plus les virus ne peuvent pas se reproduire tout seul.

C13. Le traitement utilisé contre les virus, c'est le vaccin et les antiviraux, mais les antiviraux bloquent toutes les cellules, ce qui n'est pas bien. Tandis que les bactéries se soignent avec les antibiotiques.

La complémentarité est celle des virus et des bactéries qui appartiennent - avec d'autres éléments, absents dans le cadre de ce travail - à l'ensemble des agents pathogènes. C'est dire implicitement ce que les virus et les bactéries ont en commun, et justifier ainsi la finalité qui consiste à les comparer. Le contraste active explicitement les différences recensées. La norme de validité est donc constitutive du motif de comparaison et du résultat escompté (le but de l'activité). L'exactitude des savoirs évalués en biologie vaut finalement surtout pour la justesse notionnelle du cadre d'étude, autrement dit pour le libellé des critères de comparaison (les motifs) et le mode de leurs applications. C'est dans cette mesure que nous estimons très réussi le texte C8 qui condense l'information, et en hiérarchise les données. C8 valide la pertinence des informations par la finalité qu'il a su leur conférer (implicitement).

Nous retenons enfin des analyses que tandis que construit une comparaison, dont les deux propositions partagent le même but (téléonomie), sont coorientées mais dissymétriques et dont le contenu relié est présenté comme un ensemble (un tout) dont les éléments sont présentés de façon à la fois complémentaire et contrastive. 
Nous n'irons pas plus loin dans cette discussion qui mériterait d'être reprise et complétée à l'aide de nouveaux paramètres, que Guimier n'avait pas eu la place d'introduire dans sa propre étude (où le développement sur alors que l'emporte nettement), en l'occurrence le genre d'écrit ${ }^{(22)}$, la position (initiale, finale, voire hors phrase) de tandis que $Q$, en relation avec la gestion thématique de l'énoncé et l'identité formelle du sujet syntaxique (Nom, pronom, singulier ou pluriel). Nous y reprendrions également la notion de « repère », pour lui associer le critère de position (tandis que $Q$ en position initiale ou finale) et le degré d'information présupposée dans le cas d'une position frontale (Combettes 1986 et Combettes 1998).

\subsection{L'explicitation du raisonnement (série des textes $\mathbf{R}$ )}

La troisième série de textes $(\mathrm{R})$ présente des difficultés supérieures à celles que nous avons jusque-là examinées. Trois raisons expliquent cette difficulté. La première est que les textes R évaluent une tâche complexe (l'expérience sur les bactéries). La seconde est que les textes engagent une comparaison elle-même complexe : elle porte sur des phénomènes de transformation et non plus sur des objets statiques, et les objets comparés sont trois et non plus seulement deux. La troisième raison enfin est que les textes supposent un raisonnement sophistiqué où se combinent trois dimensions, temporelle, cognitive (les savoirs convoqués et les savoirs à construire) et langagière.

Ainsi que nous avons eu l'occasion de le dire en introduction, la séquence «Rapport d'expérience sur les bactéries » en $9^{\mathrm{e}}$ privilégie l'apprentissage d'une démarche expérimentale et l'explicitation des étapes du raisonnement scientifique (but, hypothèses, description des résultats et conclusion). Le raisonnement des productions $(\mathrm{R}) \mathrm{s}$ 'apparente à une démarche hypothético-déductive : des données observées (soit une solution $\mathrm{x}$ ) au sujet desquelles un problème est posé (on se demande si la solution comporte des bactéries). Il faut conclure en résolvant le problème (on met à jour la présence de bactéries dans la solution examinée), et en s'appuyant sur des savoirs spécifiés (les propriétés des bactéries) et sur des savoir-faire adaptés (la méthode de l'expérimentation : les trois mélanges, le dosage des composants, la durée et la température de l'expérience, la neutralisation de tout paramètre parasite, et la comparaison des trois réactions). Ces savoirs sont convoqués sous la forme d'énoncés hypothétiques décrivant différents phénomènes réactifs ( $s$ 'il se passe ceci d'observable, les bactéries étant cela, alors nous avons affaire à des bactéries ; s'il ne se passe pas ceci...).

Le recueil des textes $\mathrm{R}$ fait apparaître une grande disparité dans la clarté du propos exposé. Le lecteur novice, qui n'a pas participé lui-même à l'expérience et qui n'est pas familier du protocole, doit lire plusieurs textes pour reconstituer l'observation et les conclusions qu'il faut en tirer. Certains textes d'élèves font écho à des questions que l'on a pu se poser antérieurement et apportent des réponses. C'est ainsi que le texte R2, en soi assez énigmatique, s'éclaire grâce au complément d'information que R13, par exemple, lui apporte. La différence des deux textes réside dans le fait que R13 prend soin de dissocier 1'expérience des résultats, alors même que R2 éprouve les plus grandes difficultés à gérer les deux aspects tout en en pressentant la nécessité. Les ratures et les parenthèses qui accompagnent une hésitation sur le temps de l'observation sont des indices de la difficulté de la tâche rédactionnelle:

R2 Dans le «Petri 1 » qui contient (ube eppendorf 1 avec $50 \mu 1$ de solution à tester, et $300 \mu 1$ de LB) et sans antibiotiques il y avait (maintenant) des colonies de bactéries

(22) Guimier (2000) s'appuie principalement sur des extraits narratifs et littéraires, empruntés à Frantexte. 
La difficulté, si elle a été éprouvée, est aisément surmontée par l'auteur de R13 (nous soulignons) :

R13 TE1 = boîte de pétri sans antibiotique où j'ai rajouté $50 \mu 1$ de solution (bactéries) à tester et $300 \mu 1$ de LB (milieu nutritif liquide).

TE2 = boîte de pétri avec antibiotiques où j' ai rajouté $50 \mu 1$ de solution à tester et 300 $\mu 1$ de LB.

TECO = boîte de pétri sans antibiotique où j'ai rajouté $300 \mu 1$ de LB.

Après les avoir laissé 24 heures à $37^{\circ} \mathrm{C}$, ma prof les a mis dans son réfrégirateur.

Aujourd'hui nous avons pu apercevoir les résultats:

Dans ma boîte TE1 nous voyons bien l'effet des bactéries ; la gelée qui était avant est devenue jaune. J'ai prouvé que dans la solution il y a des bactéries. [...]

Dans 1'extrait que nous venons de citer, l'auteur de R13 "rédige » à peine les données du protocole de l'expérience ${ }^{(23)}$ mais prend soin de les exposer lisiblement et précisément. Les trois premières lignes de description du protocole se lisent comme s'il s'agissait de la légende des trois schémas visualisant la composition des boîtes de Pétri. Par ailleurs R13 ne néglige pas de « raconter » l'expérience (temps ${ }^{(24)}$, acteurs impliqués, actions). Les résultats sont introduits pour ce qu'ils sont : résultat d'une observation et phénomène de transformation duquel on induit, en connaissance de cause, l'existence de bactéries.

La planification, que nous avons précédemment utilisée comme indicateur, ne présente plus le même intérêt dans la mesure où les consignes d'écriture imposent une mise en texte. Les textes $\mathrm{R}$ ne sont restitués que dans leurs deux dernières parties, en l'occurrence la description des résultats et les conclusions. Auparavant, les élèves ont écrit, dans des termes quasi identiques repris du cours, le but de l'expérimentation et les hypothèses. Les voici, empruntés à R6 :

But: il faut prouver si il y a des bactéries dans le tube.

Hypothèses : Si ce qui se trouve dans le tube sont des bactéries, on peut par conséquent les tuer avec des antibiotiques. Si ce qui se trouve dans le tube sont des bactéries, on peut donc les cultiver sur un milieu nutritif.

Les données de la démarche expérimentale, rappelées ici, vont nous aider à cerner les deux zones les plus problématiques pour les scripteurs de 9B. Il s'agit, pour une part, de la posture scientifique qu'il est demandé aux élèves d'adopter et qui n'est pas sans artifice. Les élèves doivent en effet feindre provisoirement d'ignorer que la solution testée comporte des bactéries dont ils simulent la découverte, à l'issue des étapes d'observation. D'autre part, sur le versant plus langagier, les élèves doivent affronter la difficulté du « référent évolutif» (Charolles et Schnedecker 1993) : le liquide présenté initialement est identifié comme finalement porteur de bactéries. En d'autres termes, il faut adapter la dénomination de la matière observée à l'évolution de l'expérience. Le caractère dynamique du processus de l'observation s'accompagne en outre des connaissances utiles pour interpréter à bon escient les circonstances parasites qui sont susceptibles de fausser les résultats (le Pétri de contrôle contaminé). Ces obstacles se renforcent dès lors que les

(23) Contrairement par exemple aux auteurs de R10 et de R12. R10 multiplie les détails circonstanciels et donne un tour très narratif à sa relation d'expérience. R12 procède davantage de l'explication méthodique, commençant par le résultat (ce qu'il faut savoir) et revenant ensuite à l'expérience et aux observations qui y ont conduit.

(24) Le repère du présent d'énonciation aujourd'hui en R13 est à comparer avec la mention de maintenant, qui figure entre parenthèses à la suite d'un imparfait, sans doute ressenti comme contradictoire, dans R2. 
élèves doivent paradoxalement étayer l'existence des bactéries à l'observation de leur absence (Pétri 2 qui contient des antibiotiques).

$\mathrm{Au}$-delà des constatations formelles (longueur de texte, orthographe, connecteurs), les textes de la classe de 9B diffèrent sensiblement de ceux des 9A d'un point de vue sémantique et pragmatique. Pour le montrer nous nous appuierons sur les seules conclusions des textes. Le choix de la conclusion s'explique par le fait que l'appropriation des savoirs et la perspective personnelle du scripteur s'y manifestent plus aisément que dans le texte qui précède, où il a fallu rendre compte, restituer des observations plus objectives. Par ailleurs, la focalisation sur un segment de texte plus étroit et plus rédigé facilite l'analyse.

Nous énumérons ci-dessous les deux séries de conclusion, en commençant par celles des textes de 9B (R1 à R5). Rappelons qu'il y a moins de textes en 9B parce que les élèves ont eu la possibilité de travailler par deux, ce qui n'a pas été le cas en 9A. Dans les extraits ci-dessous, nous soulignons (italique) les énoncés initiaux et les segments qui portent la trace de l'orientation argumentative. Les premières phrases de conclusion nous ont paru les énoncés les plus caractéristiques de la différence de traitement du problème à résoudre.

\section{Conclusions des rapports d'expérience en 9B}

R1. On constate que dans le petri 1 sans antibiotique les bactéries se sont dévellopé. Mais dans le pétri 2 avec antibiotique les bactéries sont mortes.

R2. On peux determiner qu'il y a des bactéries dans le «Petri 1 »parcequ'on n'a pas mit d'antibiotiques et qu'on voit des colonies de bactéries et, que dans le «Petri 2 » il n'y a pas de bactéries grâce à l'antibiotiques qui tue les bactéries.

R3. L'Antibiotique a été éfficace contre les bactéries car aucune ne s'est formé dans le pétrie antibiotique.

R4. L'antibiotique agit contre la bactérie et elle ne peut plus se dévelloppé donc elle trépace. Sans antibiotique on peut les cultiver.

R5. l'Antibiotique fait effet contre la bactèrie et la bactèrie ne peux pas se developper et meurt. Et on peut faire pousser des bactérie dans un milieu nutritif.

\section{Conclusions des rapports d'expérience en 9A}

R6. Normalement on aurait dî avoir le Petri $\mathrm{N}^{\circ} 2$ propre, sans bactèries pour prouver que ce n'est pas du milieu nutritif que poussent les bactèries. Dans le Pètri $\mathrm{N}^{\circ} 1$ les bactèries ne poussent pas, car les antibiotiques les tuent. Dans le Pètri $\mathrm{N}^{\circ} 3$ les bactèries ont poussé car toutes les conditions étaient Favorables pour leur croissance.

R7. La solution à tester contient des bactéries, car dans le Pétri 1, c'est grâce au milieu nutritif que les bactéries se sont reproduites jusqu'à recouvrir toute la surface. Ceci explique aussi par le fait que Pétri 2 est intacte, car l'antibiotique a tué toutes les bactéries.

Dans le Pétri 3, il n'y a rien à signaler, car le milieu nutritif liquide n'a aucune réaction seule.

R8. le tube contient bien des bacteries car sur le pétri 1, des bactéries se sont dévoloppées. Dans le pétri 2, il n'y a aucune bacteries qui se sont dévolopper*2 ${ }^{2}$, ce qui prouve que le tube contient des bacteries. Dans le pétri contrôle, les résultats ne sont pas ceux que j'attendais, il y a des colonies de bacteries qui se sont dévoloppées. Cela n'aurait pas dî se produire, cela veux dire que le pétri controlé a été contaminé*. Il n'aurait rien dû se dévolopper sur ce pétri.

* par l'utilisation du même outils (rateau, pipette)

$*^{2}$ car les antibiotiques ont tuer les bacteries

R9. Il y avait donc, bien des bactéries dans la solution car dans le pétri sans antibioti- 
ques (Pe1) elles ont colonisé tout le pétri et que dans le petri avec antibiotiques, il n'y a aucune trace de bactérie, elles sont toutes mortes. Mais, étrangement, nous retrouvons quelques colonies dans le pétri de contrôle qui ne devrait en avoir, étant donné qu'il n'y a pas de solution, juste du milieu nutritif. Nous expliquons cela à cause $d u$ fait que nous ayons utiliser le même tube pour mettre la solution du Pel et le milieu nutritif pour le pétri de contrôle.

R10. Nous pouvons conclure que pétri 1 c'est cultivé correctement. Pétri 2 a reposer toutes les bactéries grâce aux antibiotiques inclus dans la boîte, mais à cause d'une mauvaise manipulation de ma part pétri $\mathrm{CO}$ a été contaminé, alors que rien ne devaient poussé car il n'y avait pas $50 \mu 1$ de solution à tester. Nous pouvons donc constater que tout s'est déroulé comme prévu, seul le pétri CO qui fut contaminé.

R11. Nous avons vus qu'avec petri 1 il y avait un tapis de bactéries, donc dans le tubes il y avait des bactéries car nous avons pus les cultiver.

Dans Pétri 2 il n'y avait rien car il y avait de l'antibiotique.

Et dans Pétri Contrôle nous devion rien trouver dans la boite chez moi il y a eu une contamination de LB. Surment parce que je n'ai pas changer de rateau ou de tube eppendorf.

R12. pour conclure, l'on a pu prouver que ce qui se trouvait dans le tube était des bacteries, car grâce à la boite «TE1», il y avait un tapis de bacteries qui s'sest former. Par contre le «LB » lui n'avait aucune bactéries, sauf que par une erreur de ma part, des bactéries se sont déposées dans la boîte appelée «TECO ».Et comme je le pensais, rien a pousser dans la boîte de «TE2 » et toutes les bactéries ont été tuées grâces aux antibiotiques.

R13. Dans la solution il y a bien des bactérie, grâce a cette expérience nous l'avons pu remarqué; nous avons pu tuer ces bactéries avec les antibiotiques et nous avons pu les cultiver sur un milieu nutritif (liquide). Dans ma boîte TECO, mon milieu nutritif (liquide) a été infecter. Donc il y a des points ce qui n'aurait pas du arriver.

La conclusion de R13, «Dans la solution, il y a bien des bactéries » est exemplaire et peut nous servir de conclusion type ${ }^{(25)}$ : le constat d'existence des bactéries dans la solution y est établi à partir de l'observation et de la comparaison des résultats obtenus. L'emplacement initial et le contenu de l'énoncé conclusif répondent aux besoins de synthèse générale et à l'enjeu argumentatif inhérent au genre d'écrit (l'énoncé confirme le résultat attendu). Les arguments qui sont repris ensuite sont le développement succinct des résultats contrastés, reliés aux propriétés connues des bactéries.

Inversement, la présence de paragraphes, dans R11 par exemple, est le signe que le scripteur recommence à énumérer les résultats et qu'il ne parvient pas à atteindre la visée synthétique qui est la fonction principale de cette partie du texte. Quant à la dimension argumentative, on aura relevé dans R11 qu'elle prend un tour anecdotique et trop circonstanciel (le dernier énoncé qui fait retour sur l'anomalie du Pétri contrôle), qui peut être analysé comme un «écho » de l'effet dialogue, déjà signalé comme symptôme d'une stratégie à dominante pragmatique (Masseron 2005).

Les textes de $9 \mathrm{~A}$ correspondent tous, avec des degrés de réussite variables, à la fonction de conclusion qui est attendue. La conclusion est autant la synthèse finale d'un écrit complexe dont les parties précédentes ont été analytiques, que l'énoncé d'une thèse argumentative assortie de ses arguments de justification (car).

Dans la série des textes de 9B, nous ne voyons que R2 qui suive ce modèle : R2 constate et justifie 1'existence des bactéries dans la solution du Pétri 1. R1 s'en rapproche également, mais à un degré moindre.

(25) R9 aurait pu remplir aussi ce rôle de « modèle ». 
Ce qui est le plus frappant dans les écrits de 9B c'est leur focalisation sur l'antagonisme des bactéries et des antibiotiques.

Les indicateurs langagiers qui confirment cette interprétation sont de nature variée. Nous n'en retenons que les suivants :

- Thème d'ouverture des conclusions : l'antibiotique

- Lexique: tuer, agir contre, être efficace contre, sont mortes, trépasser. Procès dynamique et causatif (A fait que $\mathrm{B}$ meurt), conflit entre deux actants ( $\mathrm{A}$ et B).

- Généralité du propos de conclusion : bref énoncé de clôture qui rappelle que l'antibiotique tue la bactérie.

Ce point nous paraît très important dans la mesure où il montre, précisément, sur quels aspects le seuil de conception du problème posé n'est pas identique chez les élèves de 9B et de 9A. En effet, d'une part les 9B énonce en conclusion ce qui figurait comme l'une des deux hypothèses de la démarche. D'autre part les scripteurs s'en tiennent à la relation actionnelle, quasi-incarnée, de l'antibiotique et de la bactérie. On peut considérer que ce script antagoniste est le noyau de la représentation du problème posé, chez les élèves.

L'amalgame des hypothèses avec les conclusions, la difficulté à décomposer les étapes d'une observation et à déployer le raisonnement demandé sont corroborés par une confusion lexicale des contenants (boîte, tube, dans) et des contenus (solution, milieu, culture). Cette confusion (par exemple, R1) mériterait d'être étudiée dans le cadre d'un travail sur les figures de mots. Pourquoi après tout ne pas la considérer comme une métonymie? La réponse est bien évidemment que le lecteur conteste la valeur intentionnelle et contrôlée de la figure.

\section{Bilan provisoire}

Nous souhaitons dans cette conclusion, en nous fondant sur les analyses qui occupent la seconde partie de l'article, formuler un certain nombre de réflexions didactiques sur la question des savoirs disciplinaires et sur celle des activités rédactionnelles. Mais sans doute convient-il d'abord de revenir sur ce que nous avons présenté.

Les rameaux de houx et de laurier ont été observés puis décrits par des élèves de $7^{\mathrm{e}}$. Les écrits produits ont permis de sélectionner le lexique (terminologie) et le plan de texte (ordre, mise en paragraphes) comme indicateurs de maîtrise.

La comparaison d'un virus et d'une bactérie, telle qu'elle a été rédigée par des élèves de $9^{\mathrm{e}}$, répartis en deux classes de niveau distinct, a abouti à l'idée que la cohésion locale était plus facile à régir quand elle s'appuyait sur des routines syntaxiques, des régularités dans l'introduction du thème et des sous-thèmes (tandis que), et finalement sur la hiérarchie, conceptuelle ou sémantique, des termes génériques et des prédicats spécifiques. Inversement, les phénomènes de rupture sont sensibles à travers la gestion délicate des expressions référentielles et des connecteurs trop lâches $(e t)$.

Le rapport d'expérience produit par des élèves de $9^{\mathrm{e}}$ a permis de montrer que les lignes de conclusion, rédigées plus librement que le début, étaient symptomatiques de la complexité de la tâche. Ce sont elles qui traduisent les écarts les plus nets entre les textes aboutis et les écrits les plus fragiles. La conclusion de ce genre d'écrit, au moins pour le corpus que nous avons étudié, a permis de localiser le foyer des représentations standards sur le phénomène traité. Telles qu'elles sont apparues ces représentations verbalisent un certain stade de raisonnement et de savoirs qui sont en deçà des performances demandées, et d'un rapport plus distancié et abstrait à l'expérience. 
Notre propos a été de saisir les écrits des élèves dans le continuum de leur développement et les variations - conceptuelles et langagières - manifestées. La comparaison, présente dans les trois situations ${ }^{(26)}$, a été notre fil conducteur.

Il ressort de cette étude que la première situation doit privilégier les objets d'enseignement à entrée lexicale ainsi que les activités développées à partir des listes (ordre, exhaustivité, prédication simple, etc.). Le genre d'écrit auquel tendent les activités est le texte descriptif.

La seconde situation permet de travailler simultanément la répétition d'un moule syntaxique en relation avec un certain type de progression thématique (un hyperthème présentant deux entités complémentaires). Les procédures de détachement (pour, quant à) et de renomination (la bactérie comme nom plein préféré au seul pronom elle) pourraient accompagner utilement une consigne de mise en paragraphe. Enfin, il serait judicieux de rappeler, lors de la révision des textes par les élèves, que la variation du nombre s'applique à toutes les unités formelles de la chaîne d'accord. Le genre d'écrit dominant est un intermédiaire entre le texte informatif et l'explication, ayant pour objet une entité qui tend à l'abstraction.

La dernière situation, la plus complexe, nécessite peut-être des entraînements spécifiques, qui simplifient provisoirement les procédures en prenant soin de les expliciter : observer, nommer, verbaliser un lien de cause à effet ou son contraire, un lien d'effet à cause. Au plan cognitif, le rapport d'expérience - nous l'avons dit - est trompeur, puisqu'il faut prouver l'existence de quelque chose (les bactéries) par son absence. Du point de vue sémantique, il est possible que des termes apparemment anodins, en raison de leur polysémie, demeurent incompris ou mal appropriés; c'est en tout cas une des questions à vérifier au sujet de milieu (nutritif, de culture) et solution. Le genre d'écrit dominant est l'argumentation, à visée que l'on pourrait qualifier d' « objectivante ».

Pour des raisons que nous avons essayé de montrer au cours de notre étude, la comparaison se prête bien à une collaboration pluridisciplinaire et à une analyse des productions d'un point de vue local (l'énoncé) et global (le texte). Les enjeux sont à la fois cognitifs et langagiers. Cette notion nous paraît d'autant plus intéressante à travailler dans ce cadre que sa complexité l'apparente à une démarche de raisonnement (la comparaison n'est pas une simple procédure) et qu'en outre elle renvoie à des compétences disciplinaires qui sont à la fois équivalentes et spécifiques. Le biologiste en effet sait ce qui est comparable dans son domaine et, connaissant les résultats de la démarche engagée, il lui est plus facile non seulement de guider les élèves, lors d'une expérimentation par exemple, mais aussi de les observer en connaissance de cause. Le professeur de français, spécialiste de la langue et des textes, explique les structures syntaxiques et textuelles de la comparaison dans un écrit scientifique comme ceux que nous avons analysés. Il veille tout particulièrement à ce que les parallélismes de construction, les retours à la ligne et les répétitions régissent la lisibilité des propositions. Nous avons vu combien les phénomènes de rupture inopinée (changement de thème) pouvaient faire obstacle à la fluidité du texte et à la dynamique de son informativité. La cohésion locale (le suivi et les enchaînements) est le résultat conjugué d'une macro-structure clairement identifiée et d'une grammaire intuitive, disponible et suffisamment étendue (tandis que vs et). Il convient donc soit d'apporter des aides à l'écriture, sous la forme d'une matrice de texte ou d'une amorce, soit de contribuer à l'automatisation des formes et des opérations d'encodage par le rappel de règles orthographiques ou rédactionnelles simples et de moules syntaxiques utiles.

(26) Y compris dans la première (D), mais sur un mode évidemment mineur. Rappelons que, de façon implicite, la longueur ou la couleur des feuilles sont des motifs de comparaison. 
Quoi qu'il en soit, l'essentiel réside sans doute dans la conception de situations observables, au cours desquelles, grâce au cadre des savoirs et des outils, les élèves nomment des objets et des propriétés, verbalisent des observations et interagissent au sujet de la justesse de ce qu'ils énoncent respectivement (essai et erreur). S'ils conviennent d'un objet d'étude particulier et interdisciplinaire (ici, la comparaison), les enseignants se donnent de meilleures chances de mieux analyser les conduites verbales de leurs élèves. Ils ont ainsi provisoirement trouvé les conditions d'une coopération devenue plus opérationnelle.

\section{Orientation bibliographique}

ADAM, J.-M. (2005) : La linguistique textuelle. Introduction à l'analyse textuelle des discours, Paris : Armand Colin.

Astolfi, J.-P., \& DeVelay, M. (1989) : La didactique des sciences, Paris, PUF.

Astolfi, J.-P., DARot, E., Ginsburger-Vogel, Y., \& Toussaint, J. (1997a) : Motsclés de la didactique des sciences, Bruxelles : De Boeck.

- (1997b) : Pratiques de formation en didactique des sciences, Paris-Bruxelles : De Boeck.

BAKER, L. \& BROWN, A.L. (1984) : « Metacognitive skills and reading », in P.D. Pearson, M. Kamil, P. Mosenthal, 1984, 2002, 353-394.

BERTRAND-RENAUlT, S. \& MOLS, J. (1999) : Je construis mes apprentissages en sciences au premier degré. Bruxelles : De Boeck.

Bramaud Du Boucheron, G. (1981) : La mémoire sémantique de l'enfant, Paris : PUF.

BRONCKART, J.-P. (1996) : Activité langagière, textes et discours. Pour un interactionisme socio-discursif, Lausanne - Paris : Delachaux et Niestlé.

CATEL, L. (2001) : «Écrire pour apprendre? Écrire pour comprendre ? État de la la question », INRP, Aster, 33, 17-47.

Charolles, M., \& SchnedeCKer, C. (1993) : « Coréférence et identité. Le problème des référents évolutifs ", in Langages, 112, 106-126.

CLÉMENT, P. (1998) : «La biologie et sa recherche », INRP, Aster, 27, 57-93.

Combettes, B. (1986) : «Introduction et reprise des éléments d'un texte », Pratiques, 49, 69-84.

- (1998) : Les constructions détachées en français, Paris : Ophrys.

De VeCCHI, G. (1992) : Aider les élèves à apprendre. Paris : Hachette éducation.

Develay, M. (1989) : "Sur la méthode expérimentale », Aster, 8, 3-16.

Doudin, P.A. \& MARTIN, D. (1992) : De l'intérêt de l'approche métacognitive en pédagogie. Une revue de la littérature. Lausanne : Centre vaudois de recherches pédagogiques. 
FAYOL, M. (1997): Des idées au texte. Psychologie cognitive de la production verbale, orale et écrite, Paris : PUF.

FILLON, P., \& VÉRIN, A. (2001) : «Écrire pour comprendre les sciences », INRP, Aster, 33, 3-16.

Fourez, G., EGLEBERT-LeCOMTE, V., \& MATHY, P. (1997) : Nos savoirs sur nos savoirs. Bruxelles : De Boeck.

FuChS, C., \& LE GoffiC, P. (2005) : «La polysémie de comme », in O. Soutet, éd., La polysémie, Paris : Presses de 1'Université de Paris-Sorbonne, 267-292.

GARCIA-DEBANC, C. (1990): L'élève et la production d'écrits, Université de Metz, Didactique des textes.

Gross, G., \& PRANDI, M. (2004) : La finalité. Fondements conceptuels et genèse linguistique, Bruxelles : Deboeck-Duculot.

GUICHARD, J. (1998): Observer pour comprendre les sciences de la vie et de la terre. Paris : Hachette éducation.

GuIMIER, C. (2000) : « Non-congruence et congruence, alors que vs tandis que», Syntaxe et sémantique, $1,79-111$.

Halté, J.-F. (1988) : «Points de vue sur l'explicatif», Pratiques, 58, 3-11.

JACOBI, D. (2005) : Les sciences communiquées aux enfants, Grenoble : PUG.

JoshuA, S., \& DUPIN, J.-J. ((1993) 2003) : Introduction à la didactique des sciences et des mathématiques, Paris : PUF.

KOHN, R. C., \& NÈGRE, P. (1991) : Les voies de l'observation. Repères pour les pratiques de recherche en sciences humaines, Paris : Nathan Université.

LAhire, B. (1993, Culture écrite et inégalités scolaires. Sociologie de "l'échec scolaire " à l'école primaire, Lyon : PUL.

LANGUE FRANÇAISE 159 (2008) : «Points de vue sur comme», E. Moline et N. Flaux, eds, Larousse.

LAPARRA, M. (1986) : «Analyse des difficultés des élèves en matière de lecture et d'écriture des textes explicatifs », Pratiques, 51, 77-85.

MASSERON, C. (2005) : «Indicateurs langagiers et stratégies scripturales, du discours à la langue », Pratiques, 125-126, 205-249.

Peterfalvi, B., \& JACOBI, D. (2003) : «Les interactions langagières entre processus et matériaux pour la recherche », INRP, Aster, 37, 3-15.

RIVARA, R. (1990) : Le système de la comparaison, Paris : Editions de Minuit.

RUMELHARD, G. (1998) : « Au milieu des courants, constitution d'une didactique des sciences de la vie et de la terre », INRP, Aster, 27, 45-56.

\section{Textes officiels : plans d'études (Genève et cantons romands)}

PECOBIO 2001 : Plan d'études pour le cycle d'orientation, biologie (Canton de Genève).

FRANÇAIS $3^{\mathrm{e}}$ cycle, Réaménagement du plan d'études genevois. Texte d'application. Commentaires théoriques et didactiques, Guide méthodologique (à l'attention des enseignant-e-s du cycle d'orientation), 2009.

PLAN D'ÉTUDES ROMANDS (PER) 2008. 